\title{
44 REDEFINING THE TEMPORAL FRAMEWORK FOR END-OF-LIFE PLANNING: THE PLANFUL SELF-ADVOCACY MODEL
}

10.1136/bmjspcare-2011-000053.44

E Kahana', B Kahana², L Lovegreen', J Kahana', J Brown ${ }^{1}$ Case Western Reserve, $\mathrm{OH}$, USA; ${ }^{2}$ Cleveland State University, OH, USA

This paper offers a conceptual framework to help contextualize end of life planning and expand its temporal dimensions. Traditional orientations to plan for end of life are focused on advance directives, primarily dealing with removal of invasive life sustaining interventions during the weeks, days or hours prior to death. Such planning has not been successful in achieving its intended goals. The ascendance of the palliative care movement in many regions of the world allows for recognizing the importance of maximizing comfort, offering social support and respecting spiritual and existential needs for meaningfulness close to the end of life. Our framework of 'Planful Self-Advocacy' is focused on the value and promotion of proactive patient self-advocacy for eliciting responsive health care long before the patient reaches the end of life. Consideration of options for planful action as people reach old age, or as they are diagnosed with life limiting chronic illness, are presented. These options include organizing informal supports for times of need, planning environmental modifications, establishing long term relationships with health care professionals who are willing to serve as patient advocates, learning about desirable long term care options and using technology to help counteract shrinking life space near the end of life. Data from our ongoing study of elders nearing the final years of life will be used to explore the relationships between model elements. 